\title{
Oxytocin-Induced Natriuresis Mediated by the Renal Kallikrein-Kinin System in Anesthetized Male Rats
}

\author{
Keiichi Adachi ${ }^{1,2, *}$, Masataka Majima ${ }^{2}$, Makoto Katori ${ }^{2}$ and Masahiro Nishijima ${ }^{1}$ \\ ${ }^{l}$ Department of Obstetrics and Gynecology and ${ }^{2}$ Department of Pharmacology, Kitasato University School of Medicine, \\ Sagamihara, Kanagawa 228, Japan \\ Received September 13, $1994 \quad$ Accepted December 9, 1994
}

\begin{abstract}
Intravenous infusion of oxytocin (OT) $(10-100 \mathrm{nmol} / \mathrm{kg} / 30 \mathrm{~min})$ to 8 -week-old anesthetized male rats resulted in a dose-dependent increase in urine volume, which showed a peak value $30-45 \mathrm{~min}$ after the start of OT-infusion. Urinary excretions of sodium, chloride and potassium were also increased by OT, showing peak values at $30-45 \mathrm{~min}$, without any increase in the creatinine level. The natriuresis by OT was accompanied by increased excretion of urinary active kallikrein, which showed a peak value $15 \mathrm{~min}$ after the start of OT-infusion. The urinary kinin level was also increased. Intravenous infusion of a kallikrein inhibitor, aprotinin $(15 \mathrm{mg} / \mathrm{kg} / 90 \mathrm{~min})$, when started $30 \mathrm{~min}$ before the OT-infusion, significantly inhibited the OT-induced increase in urine volume and urinary excretion of sodium, chloride and potassium. Intravenous infusion of a bradykinin $\mathrm{B}_{2}$ antagonist, Hoe 140 (D-Arg[Hyp $\left.{ }^{3}, \mathrm{Thi}^{5}, \mathrm{D}-\mathrm{Tic}^{7}, \mathrm{Oic}^{8}\right] \mathrm{BK}$, $4.5 \mathrm{mg} / \mathrm{kg} / 90 \mathrm{~min}$ ), when started $30 \mathrm{~min}$ before the OT-infusion, significantly inhibited the OT-induced increases in urine volume and urinary excretion of sodium and chloride, but not that of potassium. These results indicate that the OT-infusion induces natriuresis in male rats, and more than half of the natriuresis is mediated by a concomitant increase in excretion of urinary active kallikrein and the kinin generated.
\end{abstract}

Keywords: Oxytocin, Natriuresis, Kallikrein-kinin system, Aprotinin, Hoe 140

Oxytocin (OT) is one of two major posterior pituitary hormones and shows uterotonic and milk ejection activities. However, the basal plasma OT concentrations in normal males do not differ from those in nonpregnant females and in pregnant females before labor (15-42 weeks gestation) (1). The facts suggest that OT plays some physiological roles, although yet undefined. Furthermore, the amino acid sequence of OT is different only in two amino acids $\left(\mathrm{Ile}^{3}\right.$ and $\mathrm{Leu}^{8}$ ) from that of arginine vasopressin (AVP) $\left(\mathrm{Phe}^{3}\right.$ and $\left.\mathrm{Arg}^{8}\right)$ and therefore a similarity of their functions might be suggested. In fact, the effects on renal function to increase urinary sodium excretion and urine volume have long been reported in several experimental animals $(2-10)$. OT-induced natriuresis was extensively studied by many groups, including Chan et al. (11-13). Although it has been reported that it affects the glomerular filtration rate (GFR) (7), others reported that the significant effect of $O T$ on renal function is due to renal tubular electrolytes handing, suggesting that the site of OT action is on renal tubules (14-16). Precise analysis of OT

${ }^{*}$ To whom correspondence should be addressed ${ }^{2}$. action with the isolated and microperfused rabbit cortical collecting duct revealed that OT affects the apical $\mathrm{Na}^{+}$ conductance of collecting duct cells through OT receptors, distinct from the AVP receptors, and that the effect of OT may be related to increases in the intracellular calcium concentration and cyclic AMP production (17).

The renal kallikrein-kinin system is thought to be a system that increases the urinary excretions of sodium and water $(18-20)$. An active peptide, kinin, is generated from low molecular weight kininogen by the action of tissue kallikrein secreted from renal distal tubules. Kinin binds to bradykinin $\mathbf{B}_{2}$-receptors present in the collecting tubules to induce inhibition of reabsorption of sodium and water (18-20). Even though a large amount of kinin was generated in the blood stream, no increase in the excretion of urinary kinin was observed (21), since the abundant amount of kininases are present in the proximal tubules for inactivation of kinin. This suggests that kininrelated diuresis and natriuresis may mainly depend on the renal kallikrein levels in distal tubules, if vasodilatation of the renal circulation by kinin is excluded. However, there is little knowledge about the regulation of secretion 
of renal kallikrein, except some reports describing aldosterone-induced increase (22) and high sodium loadinginduced decrease (23).

The present paper describes that infusion of OT increased urine volume and urinary excretions of sodium, chloride and potassium together with increased excretion of urinary kallikrein, which was accompanied by an increased excretion of urinary kinin. Significant inhibition of this OT-induced natriuresis by a kallikrein inhibitor and a bradykinin antagonist indicated that a part of the OT-induced natriuresis was mediated by the secreted renal kallikrein and the generated kinin.

\section{MATERIALS AND METHODS}

\section{Animals}

Male Sprague-Dawley strain rats (specific pathogenfree, 8-week-old; Shizuoka Laboratory Animal Center, Hamamatsu) were used. All rats were given normal rat chow and tap water ad libitum and were housed at constant humidity $(60 \pm 5 \%)$ and temperature $\left(25 \pm 1^{\circ} \mathrm{C}\right)$ and kept on a continuous 12-hr light/dark cycle until the experiment. They were anesthetized initially with pentobarbital sodium (Nembutal; Abbott Lab., North Chicago, IL, USA) (50 mg/kg, i.p.), and the anesthesia was maintained by occasional administration of pentobarbital sodium $(25 \mathrm{mg} / \mathrm{kg})$.

\section{Preparation}

Tracheostomy was performed with a polyethylene cannula (PE-240; Clay Adams, Parsippany, NJ, USA). The right femoral vein was cannulated with a polyethylene cannula (PE-50, Clay Adams) for infusions, and the right femoral artery was cannulated with a polyethylene cannula (PE-50, Clay Adams) for measurement of systemic arterial pressure. The urinary bladder was cannulated with a polyethylene cannula (PE-50, Clay Adams) through a small abdominal skin incision. The exposed area and the cannula exteriorized for collection of urine was then covered with a wrap film (Saran Wrap; Asahi Chemical Industries, Tokyo) for prevention of insensible perspiration from the peritoneum. Body temperature was measured by a continuous thermometer (Model CTM-303; Terumo, Tokyo) and maintained at $37 \pm 1{ }^{\circ} \mathrm{C}$ with a desk lamp and put on a heated table. All rats were infused continuously through the femoral vein with $0.9 \% \mathrm{NaCl}$ at the rate of 6 $\mathrm{ml} / \mathrm{kg} / \mathrm{hr}$ by an infusion pump (Model 235; Atom, Tokyo).

\section{Experimental procedure}

After the preparation was set up, infusion of $0.9 \%$ $\mathrm{NaCl}$ solution was started, and the preparation was allowed to stabilize for $30-60 \mathrm{~min}$. The time in which the urine flow reached the steady state was defined as the start time of the experiment (Fig. 1). The first urine sample from the bladder was collected at 15 min after the start of the experiment (time $15 \mathrm{~min}$ ), and the collection was repeated at 15 -min intervals sequentially for $150 \mathrm{~min}$ (vehicle-infused group). In the OT-infused group, $0.9 \% \mathrm{NaCl}$ solution was switched to $0.9 \% \mathrm{NaCl}$ solution containing OT (Peptide Institute, Minoh) $(10,30$ or $100 \mathrm{nmol} / \mathrm{kg} /$ $30 \mathrm{~min}$ ), which was infused for $30 \mathrm{~min}$ from 45 to $75 \mathrm{~min}$ and then switched back to the $0.9 \% \mathrm{NaCl}$ solution alone (Fig. 1). Aprotinin (Wako Pure Chemical Industries, Ltd., Osaka) $(15 \mathrm{mg} / \mathrm{kg})$ (aprotinin-treated group) or Hoe 140 (D-Arg[Hyp $\left.{ }^{3}, \mathrm{Thi}^{5}, \mathrm{D}-\mathrm{Tic}^{7}, \mathrm{Oic}^{8}\right] \mathrm{BK}$; a gift from Hoechst AG, Frankfurt, Germany) $(4.5 \mathrm{mg} / \mathrm{kg}$ ) (Hoe 140-treated group) was added to the $0.9 \% \mathrm{NaCl}$ solution alone or $0.9 \% \mathrm{NaCl}+\mathrm{OT}$ solution, and the mixed solutions were infused for $90 \mathrm{~min}$ from $30 \mathrm{~min}$ before the start of OT infusion to $30 \mathrm{~min}$ after the cessation of OT-infusion (Figs. 4 and 5). In these groups, urine samples were collected at 15 -min intervals for $150 \mathrm{~min}$ as in the infusion of $0.9 \% \mathrm{NaCl}$ solution.

The parameters measured were expressed as changes from the values in the first collection of urine (time: 15 $\min$ ).

\section{Measurement of systemic blood pressure}

The systemic blood pressure was measured by a pressure transducer (Model TP-200T; Nihon Kohden, Tokyo) through the cannula inserted into the femoral artery and recorded with a thermal array recorder (Model WS-641G, Nihon Kohden). The average value of the 15 -min period was used for estimation of the mean blood pressure (MBP).

Measurement of urine volume, urinary sodium, potassium, chloride and creatinine

Urine volume was measured by weight, which was converted to volume by specific gravity as 1 . After centrifugation at $1500 \times \mathrm{g}$ for $15 \mathrm{~min}$ at $4^{\circ} \mathrm{C}$ to remove solid debris, the supernatants were taken and urinary sodium, potassium and chloride were measured by an ion-selective electrode (Fuji Dri-Chem Slide $\mathrm{Na}-\mathrm{K}-\mathrm{Cl}$; Fuji Dri-Chem 800V; Fuji Film Co., Ltd., Tokyo) after dilution $(\times 2-10)$ with distilled water.

Excreted electrolytes were expressed in milligrams per $15 \mathrm{~min}$. After tenfold dilution of the supernatants, the urinary creatinine levels were determined by Jaffe's reaction (Creatinine-Test Wako, Wako Pure Chemical Industries, Ltd.) and also expressed in milligrams per $15 \mathrm{~min}$.

\section{Measurement of urinary active kallikrein}

The activity of the active kallikrein in urine was measured with a peptidyl fluorogenic substrate selective for 
glandular or tissue kallikrein, Pro-Phe-Arg-methyl-coumarinylamide (Peptide Institute) (24). After ten times dilution of the original urine with $0.2 \mathrm{M}$ Tris- $\mathrm{HCl}$ buffer $(\mathrm{pH}$ 7.8), $10 \mu l$ of the diluted urine was incubated with $990 \mu 1$ of $5 \times 10^{-5} \mathrm{M}$ substrate solution in $0.05 \mathrm{M}$ Tris- $\mathrm{HCl}$ buffer containing $0.1 \mathrm{M} \mathrm{NaCl}$ and $0.01 \mathrm{M} \mathrm{CaCl}_{2}(\mathrm{pH} 8.0)$. One arbitrary unit (AU) was defined as the amount of urinary kallikrein that released $10^{-12} \mathrm{~mol}$ of 7 -amino-4methyl-coumarin for $10 \mathrm{~min} / \mu \mathrm{l}$ urine at $37^{\circ} \mathrm{C}$. Active kallikrein activity was calculated as the difference between amidase activity in the presence of soya bean trypsin inhibitor $(0.5 \mu \mathrm{g} / \mu \mathrm{l}$ urine) and that in the presence of aprotinin $(0.5 \mu \mathrm{g} / \mu 1$ urine). This determination method was able to exclude proteases other than kallikrein that may be contaminating the urine (24).

\section{Measurement of urinary kinin}

In another series of experiments for the assay of kinin in urine, urine was collected directly into plastic tubes con- taining absolute ethanol via cannulas (PE-10, Clay Adams) inserted into both sides of the ureters of rats under the same experimental condition, since kinin is rapidly degraded during its presence in the bladder. Kinin levels were determined with a bradykinin enzyme immunoassay kit (Markit M bradykinin; Dainippon Pharmaceutical Corp., Osaka) (25). The amounts of kinin secreted were expressed in picograms per $15 \mathrm{~min}$.

\section{Measurement of creatinine levels in serum}

Peripheral blood $(0.15 \mathrm{ml})$ was collected through a cannula inserted into the right femoral vein at the time points of 15, 90 and $150 \mathrm{~min}$ in the vehicle-infused groups or OT-treated groups. For preparation of serum, blood was collected into glass tubes, without anticoagulant, left at room temperature for $2 \mathrm{hr}$ and then centrifuged at $1500 \times \mathrm{g}$ for $15 \mathrm{~min}$ at $25^{\circ} \mathrm{C}$. The creatinine levels of the blood samples were determined by the same method as used for urinary creatinine.
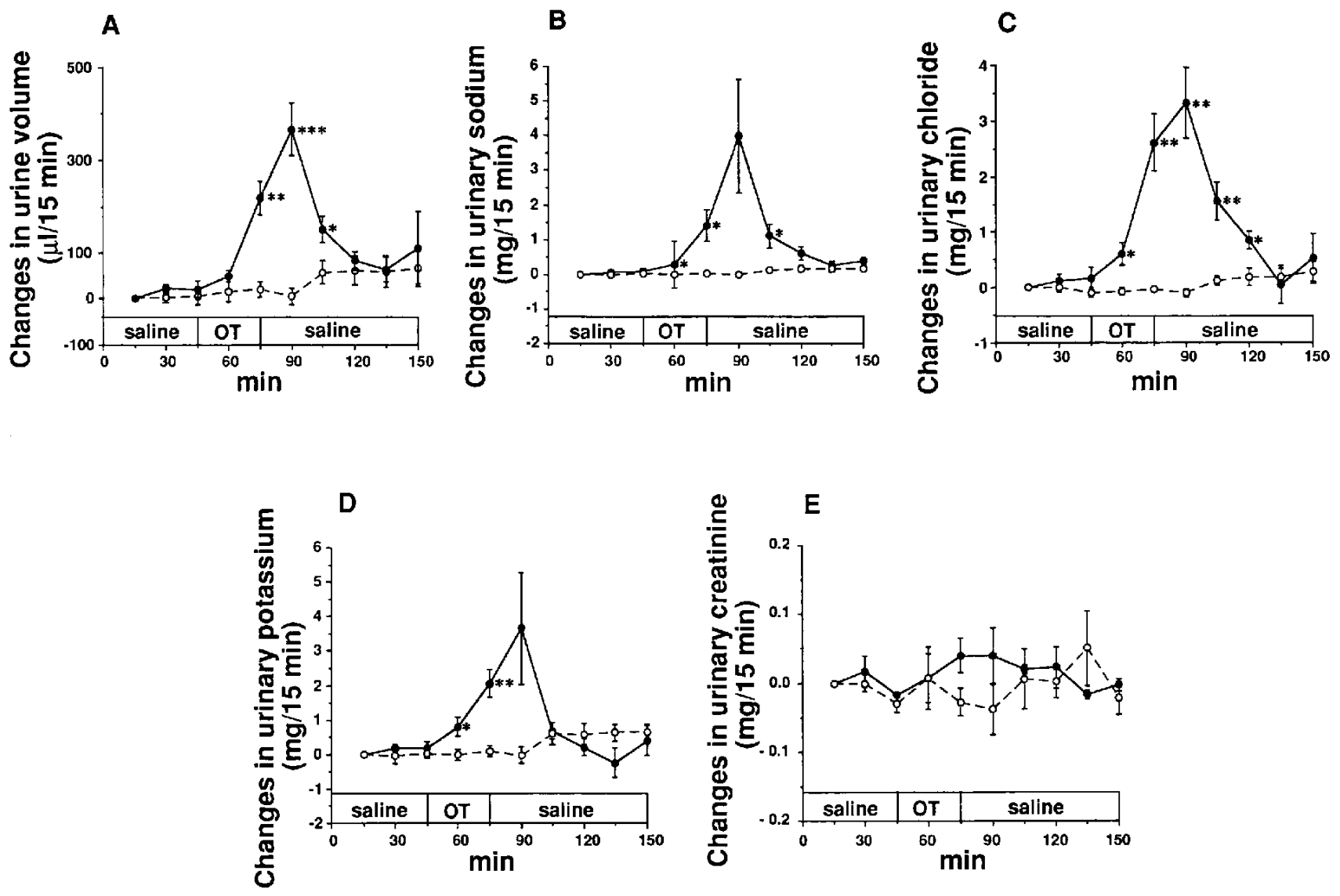

Fig. 1. Time course of the changes in urine volume (A) and urinary excretions of sodium (B), chloride (C), potassium (D) and creatinine (E) during intravenous infusion of oxytocin (OT). OT was infused at the rate of $30 \mathrm{nmol} / \mathrm{kg} / 30 \mathrm{~min}$ as shown in the scale below. The value represents the means \pm S.E.M. Each value from the OT-infused group (O) was compared with that in the vehicle-infused group (O) at the same time period $\left({ }^{*} \mathrm{P}<0.05,{ }^{* *} \mathrm{P}<0.01,{ }^{* * *} \mathrm{P}<0.001\right)$. $\mathrm{O}=6$ for $\mathrm{A}, \mathrm{n}=5$ for $\mathrm{B}, \mathrm{C}$ and $\mathrm{D}$, $n=3$ for $E, O: n=5$ for $A, B, C$ and $D, n=4$ for $E$. 


\section{Statistical analyses}

Values are expressed as the means \pm S.E.M. Significance of differences between the means was analyzed by Student's $t$-test or the paired $t$-test. A P value less than 0.05 was considered to be significant.

\section{RESULTS}

\section{Mean blood pressure}

The MBP $30 \mathrm{~min}$ before OT-infusion of $10 \mathrm{nmol} / \mathrm{kg}$ $(115 \pm 12 \mathrm{mmHg}, \mathrm{n}=5)$ and $30 \mathrm{nmol} / \mathrm{kg}(113 \pm 7 \mathrm{mmHg}$, $\mathrm{n}=4$ ) were not different from that of $0.9 \% \mathrm{NaCl}$-infusion alone $(115 \pm 7 \mathrm{mmHg}, \mathrm{n}=5)$. The OT-infusion induced slight, but not statistically significant, increase in the MBP, in such a way that the MBPs of 10 and $30 \mathrm{nmol} / \mathrm{kg}$ of OT (15 min after OT-infusion, time: $60 \mathrm{~min}$ ) were $128 \pm 9 \mathrm{mmHg}$ and $123 \pm 4 \mathrm{mmHg}$, respectively, compared with that of the $0.9 \% \mathrm{NaCl}$-infusion $(105 \pm 8$ $\mathrm{mmHg}$ ). The slight, but not significant, increase in the MBP was observed at the end of the OT-infusion (time: $75 \mathrm{~min})(127 \pm 10 \mathrm{mmHg}$ for OT-infusion of $10 \mathrm{nmol} / \mathrm{kg}$ and $130 \pm 2 \mathrm{mmHg}$ for OT-infusion of $30 \mathrm{nmol} / \mathrm{kg}$ ). In one preliminary experiment, infusion of a higher dose of OT $(100 \mathrm{nmol} / \mathrm{kg})$ markedly increased the MBP to 170 $\mathrm{mmHg}$.

Thus, the dose of $30 \mathrm{nmol} / \mathrm{kg}$ was selected for further analysis of the effect of OT, because the pressure effect was minimum, if any.

Changes in urine volume and urinary excretion of sodium, chloride, potassium and creatinine during intravenous infusion of oxytocin

Urine volume $15 \mathrm{~min}$ after the start of the experiment (time: $15 \mathrm{~min}$, the basal value) was $103.3 \pm 18.2, \mathrm{l} / 15 \mathrm{~min}$ $(\mathrm{n}=6)$. As shown in Fig. 1A, OT-infusion $(30 \mathrm{nmol} / \mathrm{kg})$ induced a significant increase in urine volume at $30 \mathrm{~min}$ after the start of OT-infusion (time: $75 \mathrm{~min})(322.4 \pm 36.1$

Table 1. Changes in serum creatinine levels during intravenous infusion of oxytocin

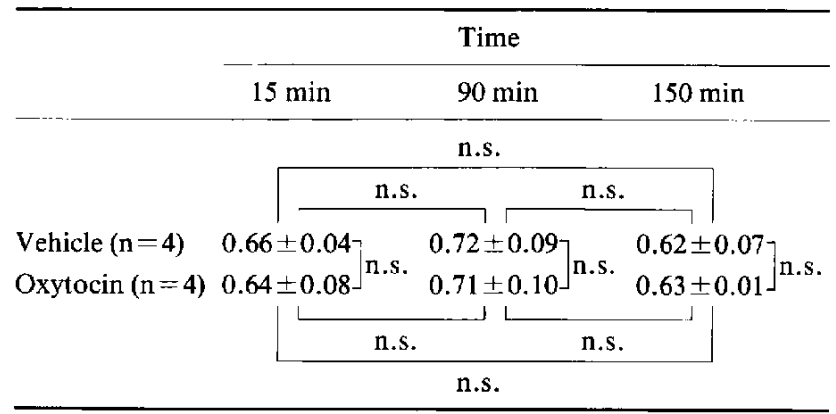

Oxytocin ( $30 \mathrm{nmol} / \mathrm{kg} / 30 \mathrm{~min}$ ) was infused for $30 \mathrm{~min}$ from $45 \mathrm{~min}$ to $75 \mathrm{~min}$. Vehicle-infused rats recieved only $0.9 \% \mathrm{NaCl}$ solution at $6 \mathrm{ml} / \mathrm{kg} / \mathrm{hr}$. Each value represents the means \pm S.E.M. $\mu 1 / 15 \mathrm{~min}$ ), showing a peak level $15 \mathrm{~min}$ after the cessation of OT-infusion (time: $90 \mathrm{~min})(469.0 \pm 56.2 \mu \mathrm{l} / 15$ $\mathrm{min}$ ). Increase in urine volume at the peak was $354 \%$ of the basal value.

The increase in the urine volume by OT-infusion was accompanied by increases in the excretions of sodium (Fig. 1B), chloride (Fig. 1C) and potassium (Fig. 1D). Excretions of sodium, chloride and potassium at $15 \mathrm{~min}$ after the start 'of the experiment (time: $15 \mathrm{~min}$, the basal value) were $0.24 \pm 0.08 \mathrm{mg} / 15 \mathrm{~min}(\mathrm{n}=5), 0.69 \pm 0.28 \mathrm{mg} / 15$ $\min (n=5)$ and $1.02 \pm 0.24 \mathrm{mg} / 15 \mathrm{~min}(\mathrm{n}=5)$, respectively. The peak value of sodium excretion was $1654 \%$ $(4.21 \pm 1.63 \mathrm{mg} / 15 \mathrm{~min})$ of the basal value $15 \mathrm{~min}$ after
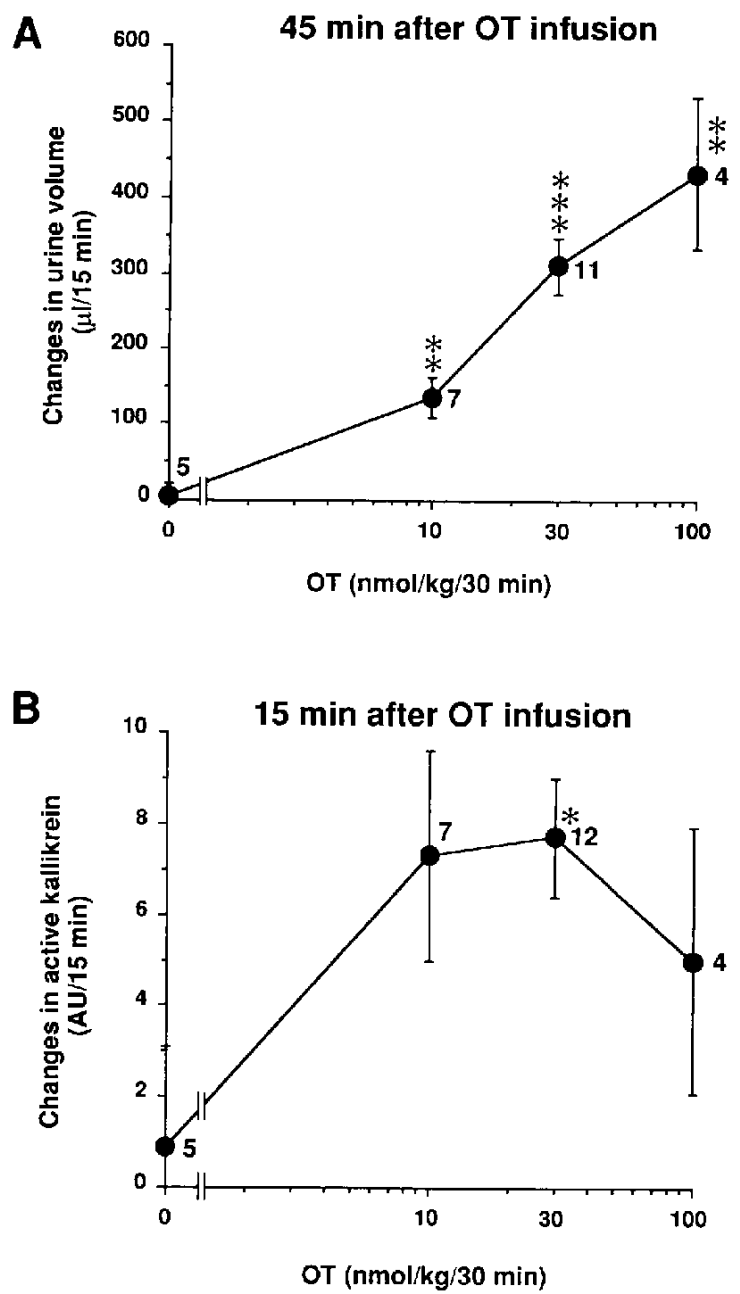

Fig. 2. Dose-response curve for increases in urine volume (A) and urinary active kallikrein excretion (B) after intravenous infusion of oxytocin (OT). OT was infused for $30 \mathrm{~min}$ following the protocol shown in Fig. 1. The peak value of the increase in urine volume was estimated to be $45 \mathrm{~min}$ after the start of OT-infusion and that in urinary active kallikrein excretion was estimated to be $15 \mathrm{~min}$ after the start of OT-infusion (peak values). Each value represents the means \pm S.E.M. Numbers of animals are shown at each value. Each value was compared with the value for vehicle-infusion $\left({ }^{*} \mathrm{P}<0.05\right.$, ${ }^{* * *} \mathrm{P}<0.01,{ }^{* * *} \mathrm{P}<0.001$ ). 
the cessation of OT-infusion (time: $90 \mathrm{~min}$ ), although the difference between the basal value and the peak value was not statistically significant. Increase in chloride at the peak $(4.01 \pm 0.64 \mathrm{mg} / 15 \mathrm{~min})$ was $481 \%$ of the basal value and was larger than that of potassium $(4.66 \pm 1.62$ $\mathrm{mg} / 15 \mathrm{~min}, 357 \%$ of the basal value), although the deviation of the peak value of potassium was large.

Urinary creatinine excretions were not changed throughout the experimental periods (Fig. 1E). The serum creatinine levels determined in the separate experiment were kept fairly constant in OT-infused rats (Table 1).

Urine volume and urinary excretion of active kallikrein and kinin after intravenous infusion of oxytocin

The intravenous OT-infusion ( $30 \mathrm{nmol} / \mathrm{kg}$ ) showed the peak value of urine volume at $45 \mathrm{~min}$ after the start of OT-infusion (time: $90 \mathrm{~min}$ ) (Fig. 1A). The increases in the doses of OT from 10 to $100 \mathrm{nmol} / \mathrm{kg}$ increased the urine volume dose-dependently (Fig. 2A). Urinary excretion of active kallikrein $15 \mathrm{~min}$ after the start of the experiment (time: $15 \mathrm{~min}$, the basal value) was $7.6 \pm 1.3 \mathrm{AU} / 15 \mathrm{~min}$ $(n=6)$. As shown in Fig. 3A, the increase in urinary excretion of active kallikrein was also observed immediately after the start of OT-infusion, and the peak value $(14.8 \pm 2.2 \mathrm{AU} / 15 \mathrm{~min})$ was observed at $15 \mathrm{~min}$ after OTinfusion (time: $60 \mathrm{~min}$ ). The level declined thereafter and was lower than the pre-injection level after the cessation of OT-injection. The lowest value was $3.5 \pm 0.7 \mathrm{AU} / 15$ $\mathrm{min}$ at $30 \mathrm{~min}$ after the cessation. Interestingly, the increase in urinary excretion of active kallikrein was observed more rapidly than the increases of urine volume, sodium, chloride and potassium, as their peak values appeared $15 \mathrm{~min}$ after the start of OT-infusion (time: 60 min) (Figs. 1 and 3A). As shown in Fig. 2B, the increased excretion of active kallikrein reached a plateau at 10 and $30 \mathrm{nmol} / \mathrm{kg}$ and declined slightly at the higher dose of OT $(100 \mathrm{nmol} / \mathrm{kg})$. Urinary kinin level was also increased slightly later than the peak of urinary kallikrein and declined gradually thereafter (Fig. 3B). In the late phase, the values were significantly higher than the basal value and those of the vehicle-infused group.

Effects of aprotinin or Hoe 140 on the OT-induced increase in the urine volume and the urinary excretions of active kallikrein, sodium, chloride, potassium and creatinine

Aprotinin, an inhibitor of both plasma and glandular kallikreins, was infused for 90 min over the OT-infusion periods (Fig. 4). Aprotinin, which may be excreted in the urine, inhibited the rapid increase in the active kallikrein activity in urine at $30 \mathrm{~min}$ after OT-infusion (time: 75 min) (2.6 $\pm 3.4 \mathrm{AU} / 15 \mathrm{~min}, \mathrm{n}=4)$ from the basal value (11.9 $\pm 2.6 \mathrm{AU} / 15 \mathrm{~min})$, and it was kept throughout the entire course of the experiment (Fig. 4B), indicating that the excreted aprotinin had an inhibitory action on kallikrein in the urine. This aprotinin-infusion resulted in the significant reduction in the increased urine volume during OT-infusion (time: $75 \mathrm{~min}, \mathrm{P}<0.05$ ) (Fig. 4A). This reduction of the increased urine volume was accompanied with marked reduction of the excretion of sodium (time: $75 \mathrm{~min}, \mathrm{P}<0.05$, Fig. $4 \mathrm{C}$ ) and chloride (time: $75 \mathrm{~min}$, $\mathrm{P}<0.05$, Fig. 4D). Although the increased urinary potassium excretions under OT-infusion was significantly reduced by aprotinin (Fig. 4E), the percent reduction (by 45\%) (time: $75 \mathrm{~min}$ ) was less than that observed in sodium (by 70\%) (time: $75 \mathrm{~min}$ ) and chloride (by 69\%) (time: $75 \mathrm{~min})$, and the values were still significantly higher than
A

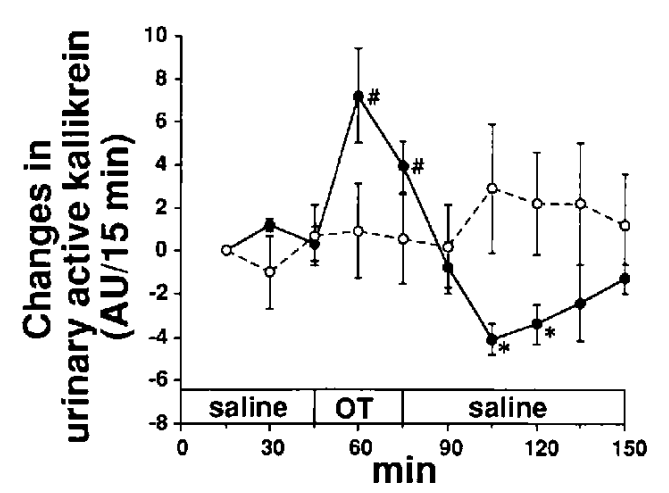

B

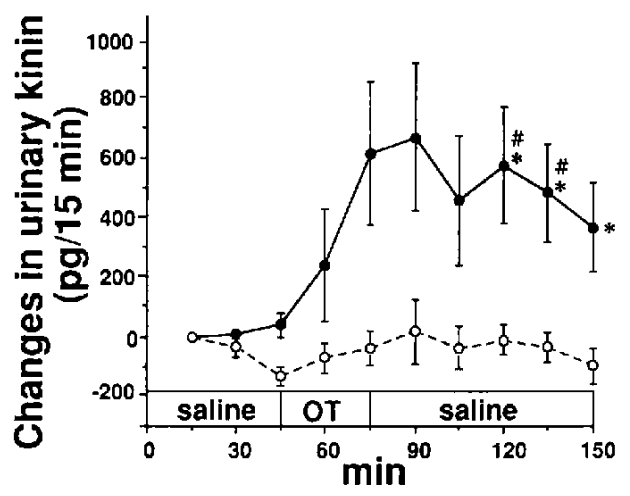

Fig. 3. Time course of the changes in urinary excretion of active kallikrein (A) and kinin (B). Oxytocin (OT) was infused at the rate of $30 \mathrm{nmol} / \mathrm{kg} / 30 \mathrm{~min}$. The value represents the means \pm S.E.M. Each value of the OT-infused group (O) was compared with that of the vehicle-infused group $(\bigcup)$ at the same time period $\left({ }^{*} \mathrm{P}<0.05\right)$. In the urinary kallikrein and kinin analyses, the values during infusion of OT were compared with that at the time of $15 \mathrm{~min}(\mathrm{P}<0.05)$. $\mathrm{n}=6$ for $\mathrm{A}, \mathrm{n}=5$ for $\mathrm{B}, \bigcirc: \mathrm{n}=5$ for A, $n=4$ for $B$. 

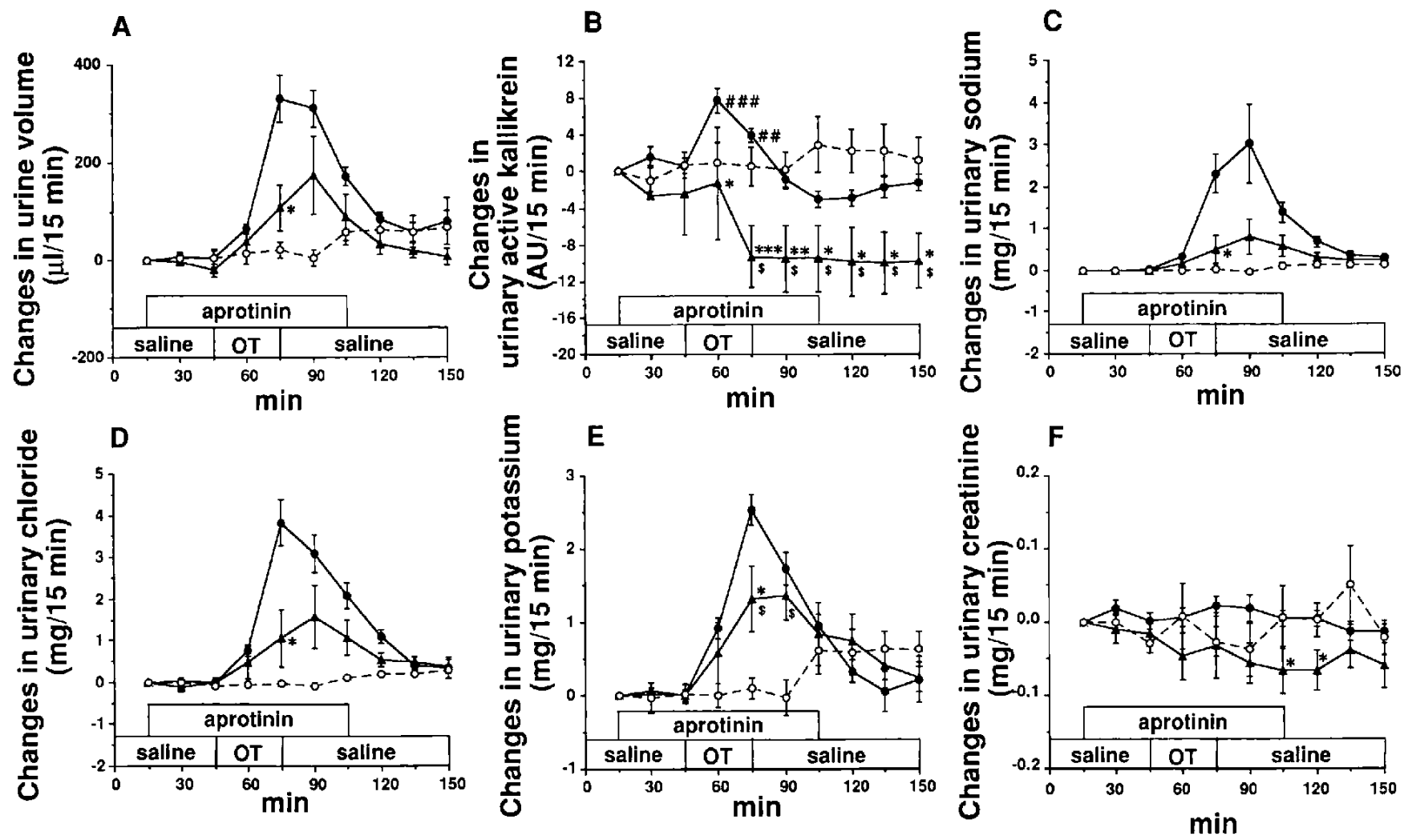

Fig. 4. Effect of aprotinin, a kallikrein inhibitor, on the increases in urine volume (A) and urinary excretions of active kallikrein (B), sodium (C), chloride (D), potassium (E) and creatinine (F) induced by intravenous infusion of oxytocin (OT). OT was infused at the rate of $30 \mathrm{nmol} / \mathrm{kg} / 30 \mathrm{~min}$, and aprotinin was infused at the rate $15 \mathrm{mg} / \mathrm{kg} / 90 \mathrm{~min}$ as shown in the scale below. The value represents the means \pm S.E.M. Each value of the aprotinin-treated group $(\mathbf{A})$ was compared with that of the aprotinin non-treated group (OT-infused group: $)\left({ }^{*} \mathrm{P}<0.05,{ }^{* *} \mathrm{P}<0.01,{ }^{* * *} \mathrm{P}<0.001\right)$ or the vehicle-infused group ( $\left.\mathrm{)}\right)$ $\left({ }^{5} \mathrm{P}<0.05\right)$ at the same time period. In the urinary kallikrein analysis, the values during infusion of OT were compared with that at the time of $15 \mathrm{~min}\left({ }^{\# \#} \mathrm{P}<0.01,{ }^{\# \#} \mathrm{P}<0.001\right)$. $\mathrm{n}=12$ for $\mathrm{A}$ and $\mathrm{B}, \mathrm{n}=10$ for $\mathrm{C}-\mathrm{E}, \mathrm{n}=8$ for $\mathrm{F}, \boldsymbol{\Delta}: \mathrm{n}=\mathbf{4}$ for $\mathrm{A}-\mathrm{F}, \bigcirc: \mathrm{n}=5$ for $A-F$.

that of the vehicle-infused group. Urinary creatinine excretion was slightly, but significantly, reduced by aprotinin-infusion, particularly in the late phase of the experiment (Fig. 4F).

Different from the kallikrein levels during the aprotinin-infusion (Fig. 4B), continuous infusion of Hoe 140, a bradykinin $B_{2}$-antagonist, did not induce any changes in the urinary kallikrein activity (Fig. 5B). However, the blockade of $\mathrm{B}_{2}$-receptors caused significant reduction of the OT-induced increases in urine volume (Fig. 5A) and excretions of sodium (time: $75 \mathrm{~min}, \mathrm{P}<0.05$; time: 135 min, $\mathrm{P}<0.01$ ) (Fig. $5 \mathrm{C}$ ) and chloride (time: $75 \mathrm{~min}$, $P<0.05$; time: 105, 120 and $135 \mathrm{~min}, \mathrm{P}<0.01$ ) (Fig. 4D). The reduced levels of urine volume, sodium and chloride were significantly higher than that of the vehicle control. It should be pointed out that Hoe 140 did not cause any changes in the potassium excretion under OT infusion (Fig. 5E). The urinary creatinine levels were kept constant (Fig. 5F), and the effect was different from that of the aprotinin-infusion (Fig. 4F).
Figure 6 shows the results of the treatment by aprotinin or Hoe 140 during the OT-infusion with the areas under the curve (AUC) from the start of the OT-infusion (time: $45 \mathrm{~min}$ ) to the end of the experimental periods (time: 150 min). The aprotinin-infusion caused the marked reduction in urinary kallikrein activity compared with that of OT alone, whereas Hoe 140 did not show any effect on the levels of secreted urinary kallikrein (Fig. 6B). As shown in the reduction rate of the AUCs of urine volume (56.6\% for aprotinin vs $50.4 \%$ for Hoe 140) (Fig. 6A) and excretion of sodium ( $71.8 \%$ vs $61.5 \%$ ) (Fig. 6C) and chloride ( $59.1 \%$ vs $48.0 \%$ ) (Fig. 6D), aprotinin reduced the AUCs essentially at the same degrees as Hoe 140 did. However, the Hoe 140 treatment did not affect the OT-induced increase in potassium excretion (Fig. 6E).

The administration of aprotinin or Hoe 140 did not significantly change the MBP of rats by OT-infusion (data not shown). 



Fig. 5. Effect of Hoe 140, a bradykinin $B_{2}$-antagonist, on the increases in urine volume (A) and urinary excretions of active kallikrein (B), sodium (C), chloride (D), potassium (E) and creatinine (F) induced by intravenous infusion of oxytocin (OT). OT was infused at the rate of $30 \mathrm{nmol} / \mathrm{kg} / 30 \mathrm{~min}$, and Hoe 140 was infused at the rate of $4.5 \mathrm{mg} / \mathrm{kg} / 90 \mathrm{~min}$ as shown in the scale below. The value represents the means \pm S.E.M. Each value of the Hoe 140-treated group $(\square)$ was compared with that of the Hoe 140 non-treated group (OT-infused group: $\left({ }^{*} \mathrm{P}<0.05,{ }^{*} \mathrm{P}<0.01\right)$ or the vehicle-infused group $(\bigcirc)\left({ }^{\S} \mathrm{P}<0.05\right.$, $\left.{ }^{\$ \$} \mathrm{P}<0.01,{ }^{\$ \$ \$} \mathrm{P}<0.001\right)$ at the same time period. In the urinary kallikrein analysis, the values during infusion of $\mathrm{OT}$ were compared with that at the time of $15 \min \left({ }^{\phi} P<0.05,{ }^{\# \#} P<0.01\right)$. $: n=6$ for $A$ and $B, n=5$ for $C-E, n=4$ for $F, \quad: n=5$ for $A-F, O: n=5$ for $A-E, n=4$ for $F$.
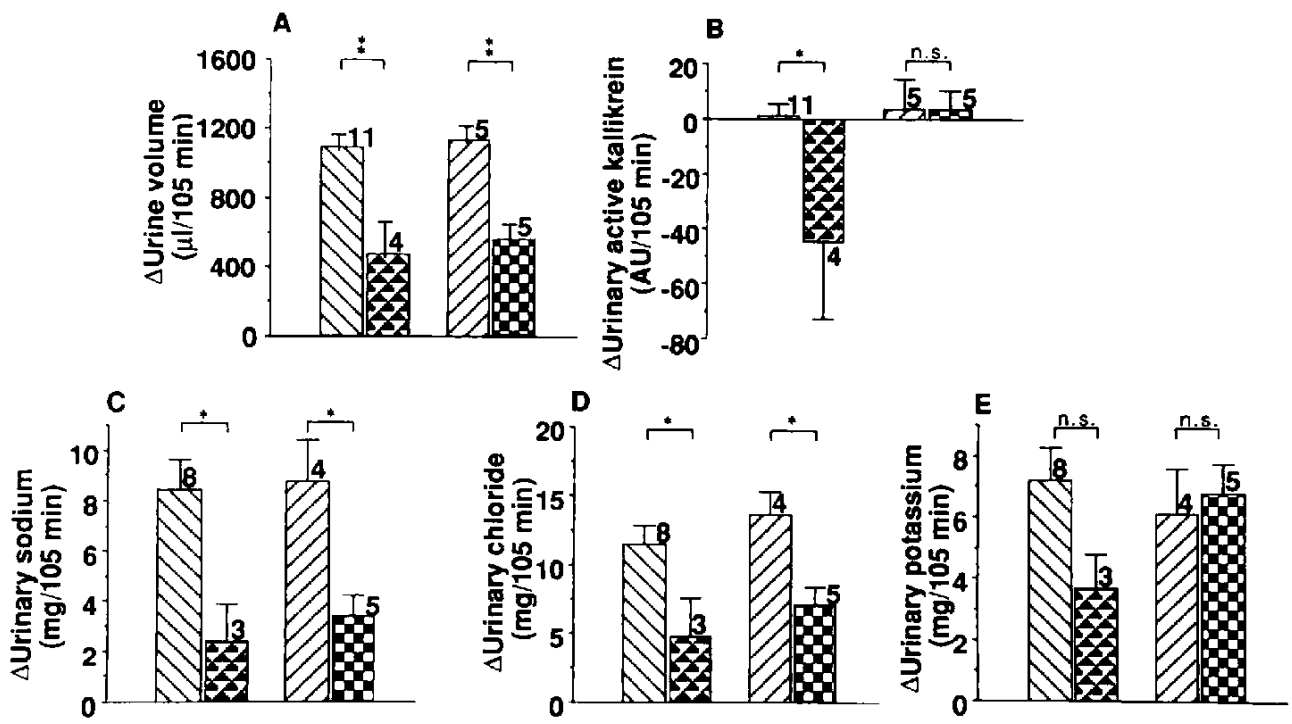

Fig. 6. Effect of aprotinin or Hoe 140 on the increases in urine volume (A) and urinary excretions of active kallikrein (B), sodium (C), chloride (D) and potassium (E) induced by intravenous infusion of oxytocin (OT). The columns indicate the area under the curve from the start of OT infusion $(30 \mathrm{nmol} / \mathrm{kg}$ ) to the end of the experimental periods (for $105 \mathrm{~min}$ ). Each value represents the means \pm S.E.M. The number at the top of each column represents the number of animals studied. Each value


$\left({ }^{*} \mathrm{P}<0.05,{ }^{* *} \mathrm{P}<0.01\right)$. 


\section{DISCUSSION}

The involvement of OT in female reproductive function is well established. The facts that OT exists in the neurohypophysis of males as well as females (26) and that the plasma concentrations of OT in males are not different from those in females (1) makes it suspicious that uterotonic and milk ejection activities are only physiological functions. In fact, the effect of this hormone on renal function has been studied for many years $(27-30)$. OT was reported to induce the increase in the urinary sodium excretion under certain physiological conditions and at pharmacological doses $(2-5)$. However, the mechanism of natriuresis of OT has not been fully understood. It has been claimed that the natriuretic action of OT was the secondary response to water retention, which was induced by simultaneous secretion of OT and vasopressin $(31-34)$. However, more recent reports on the OT activity revealed that OT has an intrinsic natriuretic action, and the natriuresis induced by [Leu $\left.{ }^{4}\right]-O T$, Lys-vasopressin, OT and [Leu $\left.{ }^{4}\right]$-Lys-vasopressin at the dose 0.7 $\mu \mathrm{g} / 100 \mathrm{~g}$, i.v. was primarily due to tubular effects without significant hemodynamic involvements $(11-13)$. The tubular action for OT-induced natriuresis was also supported by other investigators (14-16). Although the slight increase in GFR after OT administration to conscious rats was reported (35), the site of action of oxytocin in the kidney may be renal tubules, where the electrolytes reabsorption was carried out extensively (36).

Chan et al. $(11-13)$ suggested that $O T$ and its analogues inhibited sodium reabsorption primarily in the proximal tubules on the basis of the observation that increased free water excretion is often accompanied with inhibition of proximal tubular fluid absorption. Stier et al. (14) hypothesized that OT may increase urinary sodium excretion by decreasing net proximal tubular fluid reabsorption, from experiments using [Gly $\left.{ }^{7}\right]-O T$. However, Garland et al. (15) did not confirm these results and suggested from experiments using micropuncture techniques that the site of OT may be more distal in the tubules. Recently, Inoue et al. (17), using isolated and microperfused rabbit cortical collecting duct, revealed that the site of OT action is located at least at the cortical collecting duct, and OT acts through its specific receptors. As specific binding sites have been demonstrated in the inner medullary collecting duct (37), macula densa cells (38) and paraglomerular structures (39), it is plausible that $\mathrm{OT}$ exerts its natriuretic action along the tubules.

In the present experiment, the intravenous infusion of OT to anesthetized rats resulted in significant increases in urine volume and urinary excretions of sodium, chloride and potassium. The urine volume was increased by increasing doses of OT from 10 to $100 \mathrm{nmol} / \mathrm{kg}$. Thus, the natriuretic effect of OT was confirmed. In the preliminary experiment, the high dose of OT administration (100 $\mathrm{nmol} / \mathrm{kg}$ ) resulted in marked increase in the systemic blood pressure, which was accompanied with an increase in urine volume (Fig, 2). Thus the increased urine volume by the highest dose of OT may be partly due to increased systemic blood pressure. The effect of the slight increase in the systemic blood pressure during infusion of 30 $\mathrm{nmol} / \mathrm{kg}$ of OT on the increase in urine volume might be not excluded, since the plateau level of the urinary active kallikrein was accompanied with a further increase in the urine volume (Fig. 2).

Several useful techniques, such as stop-flow methods, microdisection methods and immuno-histochemical methods, have demonstrated that urinary kallikrein is secreted from the distal connecting tubules $(40-42)$. This enzyme acts on a natural and specific substrate, low molecular kininogen, to generate kinin in the tubular lumen. The kinin generated in the tubules binds to the bradykinin $\mathrm{B}_{2}$-receptors distributed over the collecting tubules (43), and the kinin inhibits sodium and water reabsorption to induce the increase in urinary excretion of sodium and water.

In the present experiment, the OT-infusion accelerated kallikrein excretion in the urine. The peak of the excretion was $15 \mathrm{~min}$ after the start of the OT-infusion, and it was $15-30 \mathrm{~min}$ earlier than the peak value of urine volume and excretions of sodium, chloride and potassium. A slight delay of the peak of natriuresis in response to OT, reported by Chan (9), may be explained by the time required for kinin formation by secreted kallikrein. The rapid decline of kallikrein excretion in the urine after cessation of the OT-infusion may indicate that OT accelerates secretion of kallikrein from renal distal tubules, and its store was exhausted by larger doses of infused OT. The kallikrein secretion was accompanied with kinin formation in the urine. The reason of the prolonged excretion of kinin in the urine was not clear, in spite of the rapid off-peak of the kallikrein excretion. One explanation may be that the urine for determination of kallikrein was collected from the bladder, but that for kinin was directly collected from the ureters for avoiding rapid destruction of kinin collected in the bladder. Renal kallikrein was also rapidly inactivated by kallistatin, a natural inhibitor, secreted from the renal tubules (44). The discrepancy in the time course of the kinin generation and the OT effect on electrolytes and urine volume might be explained by a rapid passage through a limited portion of collecting tubules, in which bradykinin $\mathrm{B}_{2}$-receptors are distributed.

The increases in urine volume and excretions of sodium, chloride and potassium by OT-infusion were reduced by aprotinin, a kallikrein inhibitor, and Hoe 140, a bradykinin $\mathbf{B}_{2}$-receptor antagonist. The inhibition rates 
of urine volume and excretions of sodium and chloride by aprotinin were $56.6 \%, 71.8 \%$ and $59.1 \%$, respectively; and they were essentially the same as those by Hoe 140 $(50.4 \%, 61.5 \%$ and $48.0 \%)$. This clearly indicates that more than half of the natriuresis by OT was attributable to that induced by the kallikrein secreted by OT and by the kinin generated by the kallikrein. The discrepancy in potassium secretion between aprotinin and Hoe 140 was obvious. The fact that Hoe 140 did not inhibit the potassium excretion supported that kinin did not accelerate the excretion of potassium. Aprotinin, which is well known to inhibit proteases other than kallikrein as a polyvalent protease inhibitor, may inhibit potassium absorption in a part of the renal tubules other than the collecting tubules in which kinin acts.

Tomita et al. reported bradykinin, administered into the renal tubules, caused the inhibition of net sodium absorption without affecting net potassium transport or the transepithelial potential difference (19), and bradykinin inhibits electroneutral $\mathrm{NaCl}$ absorption in the rat cortical collecting duct.

These results indicate that kinin accelerates renal excretion of sodium, chloride and water, but not that of potassium. Significant reduction of the creatinine level in the urine after aprotinin infusion may be explained by this non-selective inhibition, although the inhibition was not significant when estimated by AUC. In contrast, Hoe 140 is a reliable and potent bradykinin $\mathrm{B}_{2}$-receptor antagonist, and it antagonizes the actions of not only bradykinin, but also kallidin, which is a product of tissue kallikrein. Thus, it is clear that more than half of the OTinduced increase in urine volume and urinary excretions of sodium and chloride was mediated by kinin generated by the increased excretion of kallikrein.

The renal kallikrein-kinin system played a part in the total natriuresis induced by OT, suggesting that the direct action of OT itself or some other factors generated by OT may be involved in this OT-induced natriuresis. Chan proposed that the natriuretic effect of OT may be mediated in part via a renal prostaglandin mechanism (9).

Our studies using kininogen-deficient mutant rats (Brown-Norway Katholiek rats) revealed that lack of kinin generation in the urine causes hypertension by decreased urinary excretion of sodium and water and causes retention of sodium in the cerebrospinal fluid and in erythrocytes when $2 \% \mathrm{NaCl}$ in the diet was loaded (45) or a non-pressor dose of angiotensin II was infused subcutaneously (46). As the intracisternal injection of hypertonic $\mathrm{NaCl}$ solution caused increases in sympathetic discharge and vasopressin release (47), OT might be released by the same mechanism. Slight, but not significant, increases in urinary kallikrein excretion were observed in Brown-Norway Katholiek rats during the above treat- ments $(45,46)$.

In conclusion, the natriuretic action of OT was confirmed and more than half of this natriuretic action was attributable to renal kallikrein secreted by OT and to the generated kinin.

\section{Acknowledgments}

The authors wish to thank Mrs. Michiko Ogino and Miss Maki Saito for excellent technical assistance and Mr. Hiroshi Ishikawa for the construction of the excellent measuring devices. We also express sincere thanks to Prof. Richard J. Balment, Department of Physiological Sciences, School of Biological Sciences, University of Manchester, UK, for fruitful discussions and thank Drs. Kan Amano and Hajime Yoshihara for useful suggestions. This work is partly supported by Grants-in-Aid from the Ministry of Education, Sciences and Culture, Japan (\#05454581 and \#05671904).

\section{REFERENCES}

1 Leake RD, Weitzman RE, Glatz TH and Fisher DA: Plasma oxytocin concentrations in men, nonpregnant women, and pregnant women before and during spontaneous labor. J Clin Endocrinol Metab 53, 730-733 (1981)

2 Sawyer WH: Posterior pituitary extracts and excretion of electrolytes by the rat. Am J Physiol 169, 583-587 (1952)

3 Brooks FP and Pickford M: The effects of posterior pituitary hormones on the excretion of electrolytes in dogs. J Physiol (Lond) 142, 468-493 (1958)

4 Chan WY and Sawyer WH: Saluretic action of neurohypophysial peptides in conscious dogs. Am J Physiol 201, 799-803 (1961)

5 Chan WY: Effects of neurohypophysial hormones and their deamino analogues on renal excretion of $\mathrm{Na}, \mathrm{K}$ and water in rats. Endocrinology 77, $1097-1104$ (1965)

6 Balment RJ, Brimble MJ and Forsling ML: Release of oxytocin induced by salt loading and its influence on renal excretion in the male rat. J Physiol (Lond) 308, 439-449 (1980)

7 Conrad KP, Gellai M, North WG and Valtin H: Influence of oxytocin on renal hemodynamics and electrolyte and water excretion. Am J Physiol 251, F290-F296 (1986)

8 Balment RJ, Brimble MJ, Forsling ML and Musabayane CT: The influence of neurohypophysial hormones on renal function in the acutely hypophysectomized rat. J Physiol (Lond) 381, 439-451 (1986)

9 Chan WY: Renal prostaglandins and natriuretic action of oxytocin and vasopressin in rats. J Pharmacol Exp Ther 246, $603-609$ (1988)

10 Brimble MJ, Balment RJ, Smith CP, Windle RJ and Forsling ML: Influence of oxytocin on sodium excretion in the anaesthetized Brattleboro rat. J Endocr 129, 49-54 (1991)

I1 Chan WY, Hruby VJ, Flouret G and du Vigneaud V: 4-Leucine-oxytocin: Natriuretic, diuretic and antivasopressin polypeptide. Science 161, 280-281 (1968)

12 Chan WY and du Vigneaud V: Natriuretic, diuretic and anti-arginine-vasopressin (ADH) effects of two analogs of oxytocin: [4-Leucine]-oxytocin and [2,4-diisoleucine]-oxytocin. J Pharmacol Exp Ther 174, $541-549$ (1970)

13 Chan WY: An investigation of the natriuretic, antidiuretic and oxytocic actions of neurohypophysial hormones and related pep- 
tides: Delineation of separate mechanisms of action and assessment of molecular requirements. J Pharmacol Exp Ther 196, 746-757 (1976)

14 Stier CT Jr, Manning M and Sawyer WH: Natriuretic effect of [7-glycine]oxytocin in the presence of diuretic agents in conscious rats. J Pharmacol Exp Ther 212, 412-417 (1980)

15 Garland HO, Balment RJ and Brimble MJ: Oxytocin and renal function in the rat: An investigation of a possible proximal site of action. Acta Endocrinol 102, 517-520 (1983)

16 Hrbas P, Skopkova J, Zicha J, Barth T, Lebel M and Jost K: Nacartocin-analogue of oxytocin with enhanced natriuretic properties: Natriuretic and hemodynamic characteristics. Endocrinol Exp (Bratisl) 18, 117-124 (1984)

17 Inoue $T$, Naruse $M$, Nakayama $M$, Kurokawa $K$ and Sato $T$ : Oxytocin affects apical sodium conductance in rabbit cortical collecting duct. Am J Physiol 265, F487-F503 (1993)

18 Schuster VL, Kokko JP and Jacobson HR: Interactions of lysyl-bradykinin and antidiuretic hormone in the rabbit cortical collecting tubule. J Clin Invest 73, 1659-1667 (1984)

19 Tomita K, Pisano JJ and Knepper MA: Control of sodium and potassium transport in the cortical collecting duct of the rat. $J$ Clin Invest 76, 132-136 (1985)

20 Tomita K, Pisano JJ, Burg MB and Knepper MA: Effects of vasopressin and bradykinin on anion transport by the rat cortical collecting duct. J Clin Invest 77, 136-141 (1986)

21 Levy SB, Lilley J J, Frigon RP and Stone RE: Urinary kallikrein and plasma renin activity as determinants of renal blood flow: The influence of race and dietary intake. J Clin Invest 60, 129 - 138 (1977)

22 Margolius HS, Geller R, de Jong W, Pisano JJ and Sjoerdsma A: Urinary kallikrein excretion in hypertension. Circ Res 30, $358-362$ (1972)

23 Margolius HS, Horwitz D, Pisano JJ and Keiser HR: Urinary kallikrein excretion in hypertensive man: Relationship to sodium intake and sodium retaining steroids. Circ Res 35, 820-825 (1974)

24 Majima M, Katori M, Hanazuka M, Mizogami S, Nakano T, Nakano Y, Mikami R, Uryu H, Okamura R, Mohsin SSJ and Oh-ishi S: Suppression of rat deoxycorticosterone-salt hypertension by kallikrein-kinin system. Hypertension 17, 806-813 (1991)

25 Majima M, Kuribayashi Y, Ikeda Y, Adachi K, Kato H, Katori $M$ and Aoyagi T: Diuretic and natriuretic effect of Ebelactone $B$ in anesthetized rats by inhibition of a urinary carboxypeptidase Y-like kininase. Jpn J Pharmacol 65, 79-82 (1994)

26 Heller H: Occurrence, storage and metabolism of oxytocin. In Oxytocin, Edited by Caldeyro-Barcia R and Heller H, pp 3-23, Pergamon, New York (1961)

27 Balment RJ, Brimble MJ and Forsling ML: Oxytocin release and renal actions in normal Brattleboro rats. Ann NY Acad Sci 394, 241-253 (1982)

28 Peters G and Roch-Ramel F: Renal effects of posterior pituitary peptides and their derivatives. In International Encyclopedia of Pharmacology and Therapeutics, Vol 1, pp 229-278, Pergamon, New York (1974)

29 Thorn NA: The influence of the kidneys. In Handbook of Experimental Pharmacology. Neurohypophysial Hormones and Similar Polypeptides, Edited by Berde B, Vol 23, pp 372-442, Springer-Verlag, Berlin (1968)

30 Walter R, Smith CW, Mehta PK, Boonjarean S, Arruda JAL and Kurtzman NA: Conformational considerations of vasopres$\sin$ as a guide to development of biological probes and therapeutic agents. In Disturbances in Baby Fluid Osmolality, Edited by Andreoli TE, Grantham JJ and Rector FC Jr, pp 1-36, Am Physiol Soc, Bethesda (1977)

31 Leaf A, Bartter FC, Santos RF and Wrong O: Evidence in man that urinary electrolyte loss induced by Pitressin is a function of water retention. J Clin Invest 32, 868-878 (1953)

32 Schwartz WB, Bennet W, Curelop S and Bartter FC: A syndrome of renal sodium loss and hyponatremia probably resulting from inappropriate secretion of antidiuretic hormone. Am J Med 23, $529-542$ (1957)

33 Levinsky NG, Davison DG and Berliner RW: Changes in urine concentration during prolonged administration of vasopressin and water. Am J Physiol 196, 451-456 (1959)

34 Stromont JM and Waterhouse C: The genesis of hyponatremia associated with marked over-hydration and water intoxication. Circulation 24, $191-203$ (1961)

35 Conrad KP, Gellai M, North WG and Valtin H: Influence of oxytocin on renal hemodynamics and electrolyte and water excretion. Am J Physiol 251, F290-F296 (1986)

36 Berry CA and Rector FC Jr: Renal transport of glucose, amino acids, sodium, chloride, and water. In The Kidney, Edited by Brenner BM and Rector FC Jr, 4th ed, Vol 1, pp 250-251, WB Sounders Co, Philadelphia, London, Toronto, Montreal, Sidney, Tokyo (1991)

37 Stoeckel ME, Freund-Mercier MJ, Palacios JM, Richard PH and Porte A: Autoradiographic localization of binding sites for oxytocin and vasopressin in the rat kidney. J Endocrinol 113, $179-182$ (1987)

38 Stoeckel ME and Freund-Mercier MJ: Autoradiographic demonstration of oxytocin-binding sites in the macula densa. Am J Physiol 257, F310-F314 (1989)

39 Tribollet E, Barberis C, Dreifuss JJ and Jard S: Autoradiographic localization of vasopressin and oxytocin binding sites in rat kidney. Kidney Int 33, 959-969 (1988)

40 Scili AG, Carretero OA, Hampton A, Cortes P and Oza NB: Site of kininogenase secretion in the dog nephron. Am J Physiol 230, 533-536 (1976)

41 Tomita K, Endou H and Sakai F: Localization of kallikrein-like activity along a single nephron in rabbits. Pflügers Arch 389, $91-95$ (1981)

42 Vio CP and Figueroa CD: Subcellular localization of renal kallikrein by ultrastructual immunocytochemistry. Kidney Int 28 , 36-42 (1985)

43 Tomita $\mathrm{K}$ and Pisano $\mathrm{JJ}$ : Binding of $\left[{ }^{3} \mathbf{H}\right]$ bradykinin in isolated nephron segments of the rabbit. Am J Physiol 234, F732-F737 (1984)

44 Zhou GX, Chao L and Chao J: Kallistatin: A novel human tissue kallikrein inhibitor. J Biol Chem 267, 25873-25880 (1992)

45 Majima M, Yoshida O, Mihara H, Muto T, Mizogami S, Kuribayashi Y, Katori $M$ and Oh-ishi S: High sensitivity to salt in kininogen-deficient Brown Norway Katholiek rats. Hypertension 22, $705-714$ (1993)

46 Majima M, Mizogami S, Kuribayashi Y, Katori M and Oh-ishi $\mathrm{S}$ : Hypertension induced by a nonpressor dose of angiotensin II in kininogen-deficient rats. Hypertension 24, 111-119 (1994)

47 Sasaki S, Takeda K, Okajima H, Takahashi H, Yoshimura M, Nakagawa $M$ and Ijichi $H$ : Pressor responses to intracisternal injection of hypertonic $\mathrm{NaCl}$ in rats. J Cardiovasc Pharmacol 6, 349-354 (1984) 